\title{
THE SIGNIFICANCE OF HYPERHIDROSIS IN PATIENTS WITH POST-TRAUMATIC SYRINGOMYELIA
}

\author{
By P. A. Stanworth, T.D., M.A., D.C.H., F.R.C.S. \\ Department of Neurosurgery, Manchester Royal Infirmary, Manchester MI $39 \mathrm{WL}$, \\ England
}

\begin{abstract}
Eight cases of post-traumatic syringomyelia are reviewed and in each one the first symptom was excessive sweating. It is the only feature of a descending syrinx in patients with a complete cord transection. Other factors involved in the sweating are discussed.
\end{abstract}

Key words: Spinal cord injury; Syringomyelia; Hyperhidrosis

THE outlook for paraplegics has been greatly improved by the care offered by specialised spinal injury units. A late complication of spinal cord transection that is now seen in these units, post-traumatic syringomyelia,

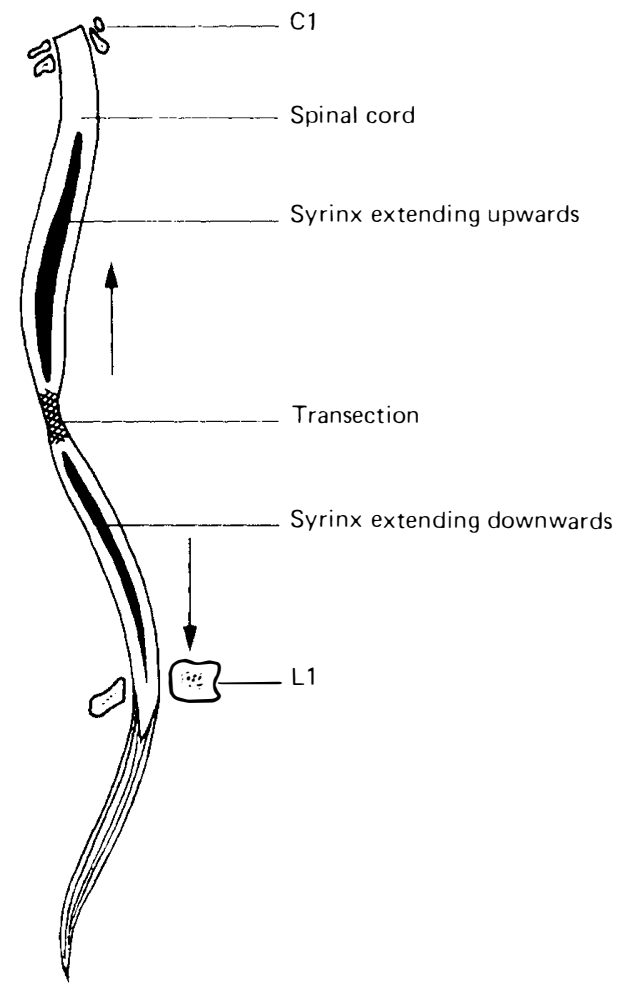

FIG. I

Syrinx cavities ascending and descending from area of cord transection. 
occurs in only a small percentage of paraplegics (Barnett and Jousse, I976), but the importance of the condition lies in the fact that it further disables them.

Examination of the spinal cord of these patients shows syrinx cavities ascending and descending within the cord from the site of damage (Fig. I). The clinical features: pain, lower motor neurone weakness and dissociated pain and temperature loss are those of syringomyelia. They develop in the previously unaffected regions above the level of cord transection and in patients with a partial cord transection below the level. The interval between trauma and presentation of syrinx symptoms varies widely but the average is IO years for a partial and 4 years for a total section (Barnett and Jousse, I976). Excessive sweating or hyperhidrosis is an early feature of the syrinx development in the paraplegic.

\section{Materials and Methods}

Eight patients have been studied clinically and some radiologically, at operation and histologically.

Case I. 36 male: At the age of 25, this man was rendered paraplegic by a motor cycle accident, with a complete cord transection at $\mathrm{T}_{4}$. He later developed severe pressure sores on his feet necessitating bilateral below knee amputations. He sought advice in the General Surgical Outpatient Department, because sweat was accumulating in the socket of the left artificial limb and causing excoriation of the skin of the stump. At times, the accumulated sweat could be poured from the limb socket. The sweating occurred over the left lower limb and left side of the trunk up to T 5 level, corresponding to his sensory level. The underlying condition was not recognised at that time and he had a surgical lumbar sympathectomy which cured the sweating up to the level of the groin. It was not until he developed dissociated anaesthesia in his left upper limb a year afterwards that syringomyelia was suspected, and five years later was confirmed at operation.

Case 2. 39 male: At the age of 30 , this man was thrown over the handlebars during a motor cycle scramble and was rendered paraplegic with a complete cord transection at T4. He presented at Neurosurgical Outpatients at Oxford with a 9 month history of weakness of his left arm, first recognised when he tried to lift himself from bed to wheelchair using a 'monkey pole'. Eighteen months earlier, he had noticed excessive waist sweating which had necessitated changing the belt of his incontinence appliance daily. The cord was explored at operation and syrinx cavities were found ascending and descending from the site of trauma, which were both drained. The waist sweating ceased immediately and his wife particularly remarked that his incontinence belt only needed washing once a week or less frequently-when it became dirty.

Case 3: 30 male: At the age of 25, this man dived into a shallow part of the River Thames, suffered an acute disc prolapse at $\mathrm{C} 6 / 7$ and was rendered paraplegic by the resulting cord transection. At 30, he committed suicide, and his spinal cord was examined at necropsy at Oxford. It showed two syrinx cavities, one ascending and the other descending from the transected region. By searching hospital records and interviewing relatives, excessive sweating was his only late onset symptom. His general practitioner sought hospital advice for the hyperhidrosis, and his sister remembers that it was impossible to rid the left side of his shirt of the odour of sweat, and the hospital notes record hyperhidrosis of one arm and both legs. 
Case 4. 39 male: At the age of 33, this man had a crush fracture of C6, when a heavy door fell off a fork lift truck struck his head a glancing blow and completely transected his cord. Six years later, he presented in the Neurosurgical Department at Manchester with a fifteen-month history of numbness and weakness of his right arm. His other complaint was of excessive sweating of his right upper limb, neck and face which necessitated changing the sheets four times each night. The hyperhidrosis was particularly provoked by warmth in bed and also by lying on his left side with the right side uppermost. It was not provoked by voiding urine, the vibration of which he would feel in his catheter. Pools of sweat would accumulate in bed. He gave up wearing pyjamas because they became soaked and gave rise to pressure sores and used a sheepskin to absorb the moisture. His wife dated the onset of the sweating four years prior to presentation. Syrinx drainage at operation has stopped the sweating.

Case 5. 4I male: This $4 \mathrm{I}$-year-old miner had an incomplete cord transection at the age of 26 , when he fractured his spine at TI2/LI in a mining accident. He presented in the Neurosurgical Department at Newcastle upon Tyne with a year's history of numbness and weakness of his left upper limb and trunk. On further enquiry, sweating had been a problem eighteen months from presentation and had spread to involve the left trunk, arm and face necessitating changing his shirt three times per day. He himself traced a clear demarcation line down the centre of his trunk between the dry and sweaty skin. He was able to wring the sweat out of his shirt and found that having dressed after a bath, the left side of his shirt would be soaking with sweat. It was particularly bad during the warmth of summer. Shaving was difficult because he was unable to get a good lather on the left side of his face. A syrinx cavity was demonstrated radiologically, and was drained surgically at $\mathrm{T} 8$ level.

Case 6. 37 male: This ex-boiler cleaner broke his back at the age of 27 when a piece of clinker fell on to his spine and completely transected his cord at TII/I 2 level. He presented in the Department of Neurosurgery, Newcastle upon Tyne with a four month history of pain, weakness and numbness of his right shoulder and upper limb. A year before presentation he noticed sweating of his right upper limb which made his sheepskin, which he always used in bed, sodden. He removed the sheepskin ('thought it was buggered') and replaced it with a towel. When it was severe, rivulets of sweat would run down his right arm and he particularly noticed it was provoked by lying on his right side and by heat generated during exercise, for example after playing basket ball. A syrinx cavity was demonstrated radiologically, and was drained surgically at T8 level.

Case 7. I7 male: This boy broke his neck on a trampoline with a complete cord transection at $\mathrm{C}_{5} / 6$, I 4 months before presentation at the Department of Neurosurgery, Manchester. He had a 6 month history of low back pain which prevented him from sitting in a wheelchair. A month prior to the onset of pain, he noticed sweating between the shoulder blades which soaked through his shirt. His aunt also noticed pools of sweat in bed when he was lying on his side. Several syrinx cavities were found when the cord was explored at operation.

Case 8. 34 male: At the age of 20, this 34-year-old computer operator broke his neck at $\mathrm{C}_{5}$ when he was thrown off his motor cycle horizontally into the side of a car. He suffered a partial cord transection and at first was tetraplegic but later partially recovered, being left with a Brown-Séquard Syndrome with a right sided weakness. He presented to the Department of Neurosurgery at Manchester with a 6 week history of headaches and left sided weakness and numbness. Four months before presentation, after straining fitting a gear box into a car, he started to sweat between the shoulder blades, and developed pain in this 
region. The sweating became worse and he put a sheepskin in his bed to absorb the moisture. On one occasion when out shopping, his legs felt very weak and he sat down in a chair. His upper trunk sweated so profusely that it soaked through a vest, shirt, thick pullover and stained the back of the chair. The spinal cord was explored at operation and was found to be flattened and widened above and below the area of original damage, suggesting cord cavitation.

\section{Results}

In seven out of the eight patients, hyperhidrosis was the first clinical symptom to appear in the development of the late onset features of syringomyelia. In one of the eight, (patient no. 8) pain and sweating probably occurred at the same time. The findings are summarised in Table I. In only two out of the eight patients was sweating one of their main complaints; in the others the history was obtained on enquiry.

TABLE I

Time of onset of syrinx symptoms prior to presentation

\begin{tabular}{cccc}
\hline Patient & $\begin{array}{c}\text { Period after } \\
\text { Trauma }\end{array}$ & $\begin{array}{c}\text { Duration of } \\
\text { Sweating }\end{array}$ & $\begin{array}{c}\text { Duration of } \\
\text { Other Features }\end{array}$ \\
\hline I & I I years & I year or more & 1 \\
2 & 9 years & I 8 months & 9 months weakness \\
3 & 5 years & I year or more & 0 \\
4 & 6 years & 4 years & I year numbness and weakness \\
5 & 6 years & I months & I year numbness and weakness \\
6 & I y years & I year & 9 months pain and numbness \\
7 & I4 months & 7 months & 6 months pain \\
8 & I4 years & 4 months & 4 months pain \\
\hline
\end{tabular}

\section{Discussion}

The abnormal pattern of sweating in paraplegics has been extensively studied by Guttman and others (Guttman, I976). If the transection occurs in the region of the sympathetic outflow then in response to increased central temperature, there is usually a 'compensatory' hyperhidrosis above and reduced but patchy sweating below the level. Sweating is also provoked by visceral reflexes, for example, bladder emptying.

The sweating of the paraplegic with a syrinx has been documented by Barnett in his monograph on Syringomyelia (Barnett et al., I973) but it is not widely recognised as a feature of this condition. In two recent reviews of post-traumatic syringomyelia, it was not mentioned in one (Shannon et al., I98I) and only in two out of ten in another (Williams et al., I98I). This is probably because this is unconnected by the patient with his other late onset symptoms such as the more obvious pain, weakness and numbness which bring him to seek medical advice. Direct questions about sweating, for example the use of sheepskins or towels in bed, the ability to wring sweat out of clothing, multiple changes of clothing during the day or staining of clothing may be helpful. 
The special features of the hyperhidrosis of post-traumatic syringomyelia have not been specifically detailed.

They are:

I. It occurs above or below the level of transection.

2. It occurs in dermatomes whose sensation is later altered by the syrinx.

3. Excessive quantity (for example, pools of sweat in bed, sweat can be wrung out of clothes).

4. It may be affected by posture (provoked by lying on one particular side).

5. It is probably related to central temperature but not to visceral reflexes.

6. In patients with a complete cord transection who are 'neurologically silent' below the level, it is the only indicator of a descending syrinx cavity.

7. The hyperhidrosis ceases after surgical syrinx drainage.

The significance of the sweating is that it is the earliest pointer to the development of cord cavitation. Syringomyelia threatens the already precarious independence of these patients with its associated additional weakness and sensory loss. The progress of the disease can be arrested and symptoms can often be improved by surgery. It is vital, therefore, that those concerned with the management of paraplegics detect the condition as early as possible.

\section{SUMMARY}

Eight patients are described with post-traumatic syringomyelia. In each of the eight, excessive sweating was the first feature of the disease, although it was only the main problem with two. Usually specific enquiry must be made to elicit the history of hyperhidrosis. The special features of the sweating are: it may occur above or below the level of transection; it tends to occur in dermatomes whose sensation is later altered by the syrinx; it is of excessive quantity; it may be affected by posture; it is related to central temperature but not to visceral reflexes; in patients with a complete cord transection who are 'neurologically silent' it is the only indicator of a descending syrinx; it ceased after surgical drainage of the syrinx cavity.

\section{RÉSUMÉ}

Huit cas avec syringomyélie post-traumatique sont rapportés. Dans châque des huit cas, la suée excessive était le premier symptome de la maladie. Bien qu'il fusse la problèm la plus pressée avec les malades, ordinairement une démande directe doit être fait de tirer l'histoire du hyperhydrose. Les symptomes spécials de la suée sont: elle peut arriver au dessus ou au dessous du niveau du fracture: elle tend arriver en dermatomes dont la sensation est changée plus tard par la cavité: il y a une quantité de soueur trés grande: elle peut être changée par la posture: elle est associée à la température centrale mais pas aux réflexes visceraux: dans les malades dont la dechirure de la moelle est complète et qui n'ont pas des symptomes neurologiques, la suée excessive est la seule indication d'une cavité descendante: elle est abolit après l'écoulement surgical de la cavité.

\section{ZUSAMMENFASSUNG}

Es wird über acht Fälle von posttraumatischer Syringomyelien berichtet. Ubermässiges 
Schwitzen war bei allen acht Patienten das erste Merkmal der Krankheit, obwohl es nur für zwei unter ihnen die Hauptproblem war. Meistens muss man spezifische Erkundigungen einziehen, um die Entwicklung der Hyperhydrosis zu entlocken. Die besonderen Merkmale des Schwitzens sind hiermit beschrieben: das Schwitzen kann über oder unter dem Rückenmarkriss entstehen; es neigt in Dermatomen vorzukommen, deren Sinnesempfindung von der Syrinx später verändert wird; es ist übermassig; die körperliche Haltung kann darauf wirken; es steht in Beziehung zu der zentralen körperlichen Temperatur, doch nicht zu der Reflexbewegung des Eingeweides; es ist die einzige Andentung über eine hinunterfallende Syrinx bei Patienten dessen Rückenmarkriss vollkommen ist, und die 'neurologisch schweigend' sind; es hörte nach chirurgischer Drainage der Syrinxkavität auf.

Acknowledgements: I am most grateful to all the consultants who have allowed me to use information relating to their patients in preparation of this paper, namely, Mr C. B. T. Adams, Oxford; Mr John Dutton, Manchester; Mr M. Feldman, Birmingham; Professor J. Hankinson, Newcastle upon Tyne; Dr J. T. Hughes, Oxford and Mr F. A. Strang, Manchester.

\section{REFERENCES}

Barnett, H. J. M., Foster, J. B. \& Hudgson, P. (1973). In: Syringomyelia, pp. I39-I42, W. B. Saunders Company Limited, London.

Barnett, H. J. M. \& Jousse, A. T. (I 976). Post-traumatic syringomyelia (cystic myelopathy). In: Handbook of Clinical Neurology. Vol. 26, I I3-I57. P. J. Vinken and E. M. Bruyn (eds.), North Holland Publishing Co., Amsterdam.

Guttman, L. (1976). Disturbances of thermoregulation. In: Spinal Cord Injuries, 2nd ed., pp. 305-330. Blackwell Scientific Publications, Oxford.

Shannon, N., Symon L., Logue, V., Cull, D., Kang, J. \& Kendall, B. (I98I). Clinical features, investigation and treatment of post-traumatic syringomyelia. $\mathcal{F}$. Neurol. Neurosurg. Psychiat., 44, 35-42.

Williams, B., Terry, A. F., Jones, H. W. F. \& McSweeney, T. (I98I). Paraplegia, 19, $67-80$. 